\title{
TREE STEM AND CANOPY BIOMASS ESTIMATES FROM TERRESTRIAL LASER SCANNING DATA
}

\author{
K. Olofsson ${ }^{\mathrm{a}, *}$ J. Holmgren ${ }^{\mathrm{a}}$ \\ ${ }^{a}$ Swedish University of Agricultural Sciences, 90183 Umeå, Sweden - (kenneth.olofsson,johan.holmgren)@slu.se
}

Commission III, WG III/1

KEY WORDS: Terrestrial laser scanning, biomass, stem, canopy

\begin{abstract}
:
In this study an automatic method for estimating both the tree stem and the tree canopy biomass is presented. The point cloud tree extraction techniques operate on TLS data and models the biomass using the estimated stem and canopy volume as independent variables. The regression model fit error is of the order of less than $5 \mathrm{~kg}$, which gives a relative model error of about $5 \%$ for the stem estimate and 10-15\% for the spruce and pine canopy biomass estimates. The canopy biomass estimate was improved by separating the models by tree species which indicates that the method is allometry dependent and that the regression models need to be recomputed for different areas with different climate and different vegetation.
\end{abstract}

\section{INTRODUCTION}

In recent years there has been an increased interest in using terrestrial laser scanning (TLS) as a tool in forest inventory (Liang et al., 2016). The emphasis has been to estimate forest variables such as stem diameter at breast height and tree height (Olofsson et al., 2014) as well as modelling the stem profile (Thies et al., 2004, Henning and Radtke, 2006, Maas et al., 2008, Liang et al., 2014, Mengesha et al., 2015, Olofsson and Holmgren, 2016) and branches (Raumonen et al., 2013).

The assesment of above ground biomass of trees is essential when evaluating tree populations in forests (Olschofsky et al., 2016). Therefore there is a need to automate the measurements. There are a number of studies that have shown that the estimate of tree biomass can be improved using TLS compared to traditional biomass models (Yu et al., 2013, Kankare et al., 2013, Hauglin et al., 2013, Calders et al., 2015). The techniques could for instance be used to estimate biomass in densely stocked young tree plantations (Seidel et al., 2013) or when modelling the tree biomass change (Srinivasan et al., 2014).

In this study an automatic method for estimating both the tree stem and the tree canopy biomass is presented. The point cloud tree extraction techniques operate on TLS data and models the biomass using the estimated stem and canopy volume as independent variables.

\section{METHODOLOGY}

\subsection{Field Data}

The field trees were sampled from the Flakaträsk site in northern Sweden (64 16'13.53” N, 18²9'52.59” E), Table 1. Eight spruce and eight pine trees were cut down and the biomass of the stems, branches and needles were measured in the field (Goude, 2016). The biomass of the branches and needles were combined to a canopy biomass class.

\footnotetext{
${ }^{*}$ Corresponding author
}

The terrestrial laser instrument used in the measurements was a Trimble TX8 with a field of view: $360^{\circ} \times 317^{\circ}$, beam divergence $0.34 \mathrm{mrad}, 1 \mathrm{million}$ laser points per second and wavelength 1.5 $\mu \mathrm{m}$ (Near-IR). A multiscan setup was used with three instrument positions surrounding each tree, Figure 1.

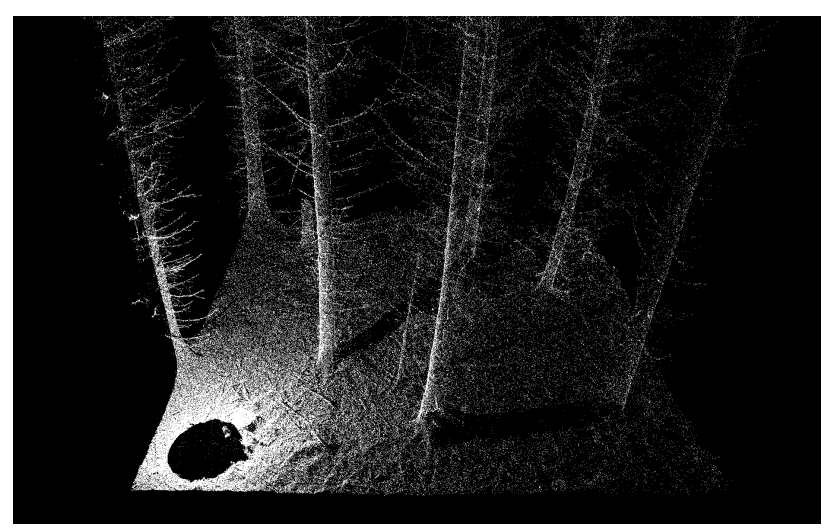

Figure 1. Example of a point cloud from a laser scanned forest plot. Shading occur behind the trees and under the measuring instrument. The number of shaded areas can be reduced if several instrument positions are used.

\subsection{Stem and Canopy Volume Extraction Algorithms}

The stems of the trees were detected and modelled using a TLS single tree extraction algorithm (Olofsson and Holmgren, 2016) which is based on the idea that stems are approximately smooth and shaped like cylinders. A voxel- based model was used where small patches of the stem surfaces were extracted using eigen decomposition of the laser point cloud (Olofsson and Holmgren, 2016).

The stem surface patches were connected and the center of the stem was estimated by calculating the curvature of the stem surface. All points that belong to stem surface patches pointing to the same center were classified as stem points, Figure 2,3. All connected stem points were used to fit cylinders as models of part 


\begin{tabular}{|c|c|c|}
\hline Species & DBH $[\mathrm{mm}]$ & Height $[\mathrm{m}]$ \\
\hline Pine & 206 & 17.2 \\
Spruce & 116 & 10.1 \\
Pine & 170 & 15.3 \\
Spruce & 180 & 12.4 \\
Spruce & 87 & 8.2 \\
Spruce & 134 & 12.4 \\
Pine & 160 & 15.7 \\
Spruce & 103 & 11.0 \\
Pine & 182 & 16.6 \\
Pine & 112 & 12.4 \\
Pine & 194 & 16.0 \\
Spruce & 64 & 6.8 \\
Spruce & 125 & 11.5 \\
Pine & 236 & 15.9 \\
Spruce & 147 & 12.4 \\
Pine & 142 & 15.3 \\
\hline
\end{tabular}

Table 1. Stem diameter at breast height and tree height for the field trees

of the stems (Olofsson and Holmgren, 2016). Stem cylinders positioned above each other were connected to stems. In this way a stem curve was extracted using cylinders with decreasing radius as a function of height.

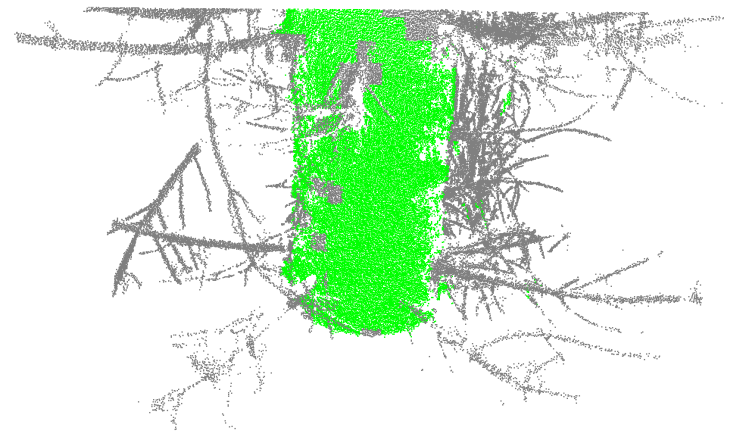

Figure 2. A laser scanned point cloud of part of a tree. The data observations that were classified as stem points by the filter algorithm are coloured green.

Once the cylinder models of the stems were calculated, the volume of the stems were estimated by the modelled stem cylinders. The top part of the tree, where the single tree detection algorithm was unable to detect stem cylinders, was modelled as a cone reaching the highest registered laser point in the canopy.

The horizontal positions of the detected stems were used when extracting the canopies of the trees. All laser points within the search radius $1.5 \mathrm{~m}$ from a stem was designated to a tree. The closest stem was chosen if a point was within the search radius of several trees.

The point clouds of each tree were subdivided into three classes: stem, canopy and understory, Figure 4 . The stem points were classified by the TLS single tree extraction algorithm (Olofsson and Holmgren, 2016). The understory points were classified as all non stem points below $2 \mathrm{~m}$. The remaining points were classified as canopy.

The tree crowns were modelled as circles surrounding the detected stems, Figure 4 . The laser points classified as canopy was

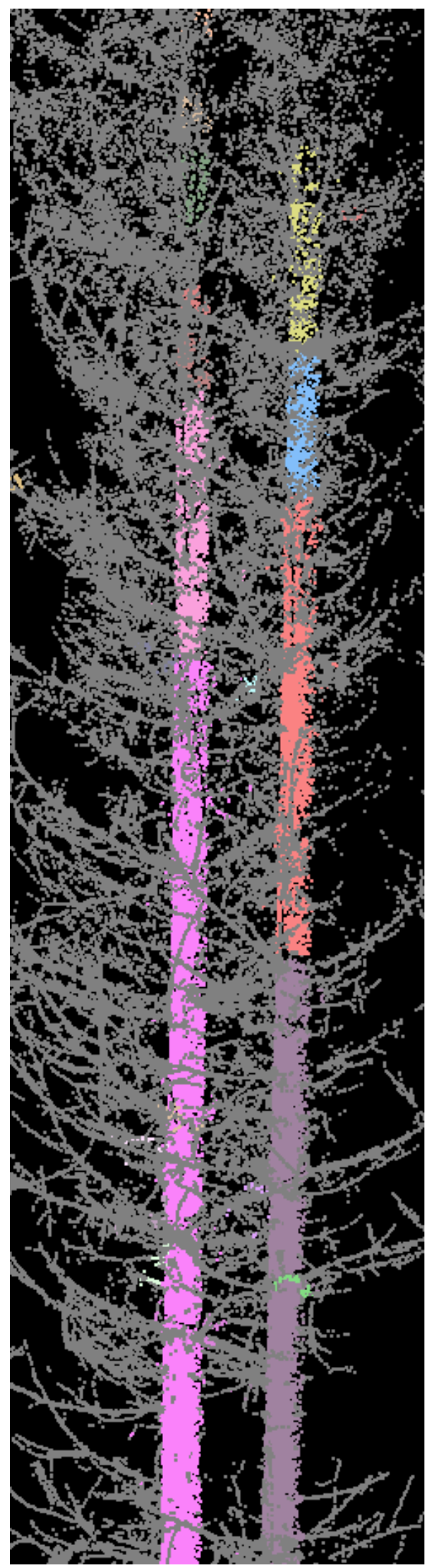

Figure 3. A laser scanned point cloud of two trees standing close together. The data observations that were classified as non stem points by the filter algorithm are coloured gray. The data points classified as stem points are used when cylinder fitting stem segments. 
used in the estimate of the crown volume. The average laser point distance to the estimated stem line was used as an estimate of the canopy radius at each 0.5 meter height interval. The canopy volume was estimated as the sum of the volume of the conical frustrums connecting two consecutive crown circles, Equation 1.

$$
V_{\text {frustrum }}=\frac{\pi h}{3}\left(r_{1}{ }^{2}+r_{1} r_{2}+{r_{2}}^{2}\right)
$$

where $V_{\text {frustrum }}$ is the volume of a conical frustrum, $r_{1}$ and $r_{2}$ are the radii of two consecutive circles and $h$ is the height interval between the two circles.

\subsection{Biomass Models}

Models of the tree stem and canopy biomass were estimated using linear regression, Equation 2,

$$
M_{b i o}=k V_{t l s}+m
$$

where $M_{b i o}$ is the biomass of the stem or canopy (branches and needles), $V_{t l s}$ is the TLS estimated volume of the stem or canopy, $k$ is the slope of the line, and $m$ is the $y$-axis intersection of the line.

The model fit of the regression lines were evaluated using the root mean square error RMSE, Equation 3,

$$
R M S E=\sqrt{\frac{\sum_{i=1}^{n}\left(x_{i}-y_{i}\right)^{2}}{n}}
$$

where $x_{i}$ is the modeled biomass of tree number $i, y_{i}$ is the observed biomass of tree number $i$ and $n$ is the number of trees.

\section{RESULTS AND VALIDATION}

The field data and the stem and canopy biomass linear models are shown in Figure 5 and Figure 6. The estimate of the canopy biomass is improved if the models are separated by tree species, Figure 6, Table 2. This is probably due to the fact that spruce canopies are more dense than pine canopies. This means that more accurate models for above ground biomass could be developed if tree species are detected automatically.

The regression model fit error is of the order of less than $5 \mathrm{~kg}$, which gives a relative model error of about $5 \%$ for the stem estimate and $10-15 \%$ for the spruce and pine canopy biomass estimates, Table 2. These values are comparable to other studies where for instance (Yu et al., 2013) received a RMSE of $12.5 \%$ for stem biomass and (Hauglin et al., 2013) retrieved an above ground biomass of $12.9 \%$ and $11.9 \%$ overall accuracy for Scots Pine and Norway spruce respectively. (Calders et al., 2015) retrieved a RMSE of $9.7 \%$ for 65 Eucalyptus leucoxylon, microcarpa and tricarpa using multi-scan TLS.

The fact that the canopy biomass estimate was improved by separating the models by tree species indicates that the method is allometry dependent and that the regression models need to be recomputed for different areas with different climate and different vegetation. This should however be possible to do for a number of regions in each country. The models for stem biomass seems to be less dependent on tree species.

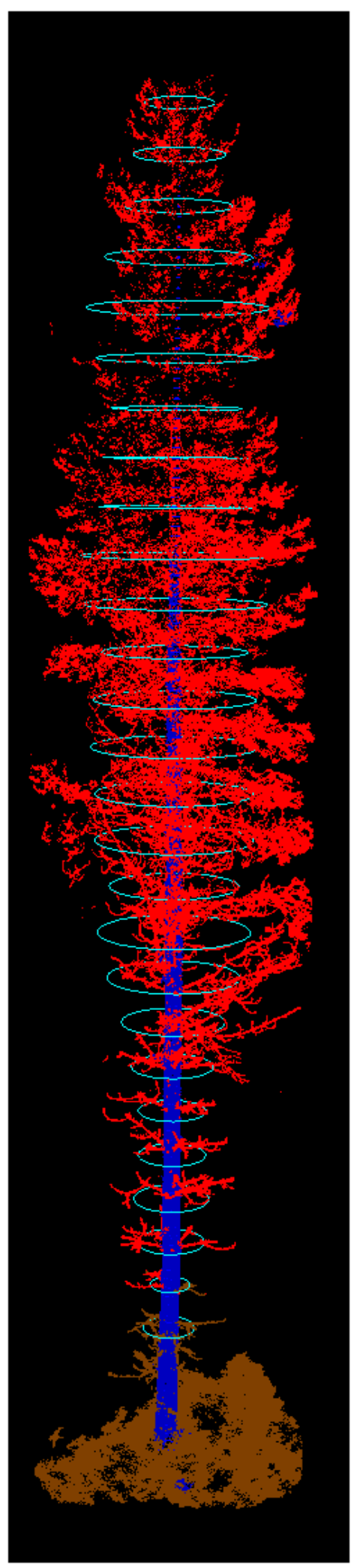

Figure 4. Terrestrial laser scanner data classified into tree stem (blue), understory (brown) and canopy (red). The radii of the light blue circles are the average distances from the stem of the canopy points at each height interval. 


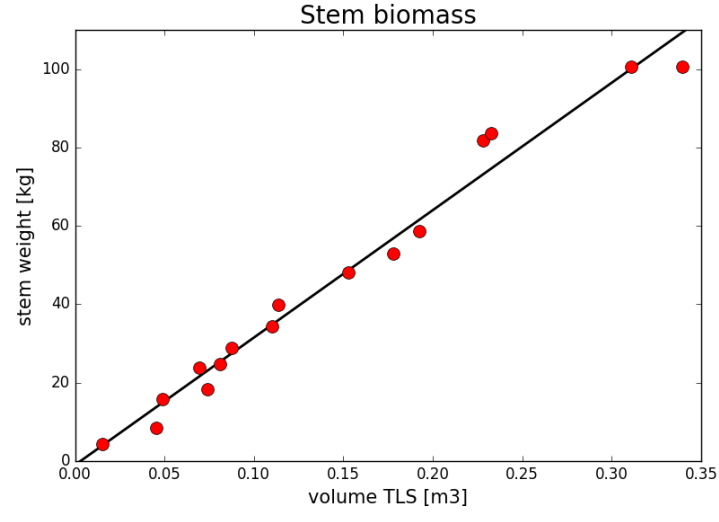

Figure 5. A linear model of stem biomass using TLS estimated volume as independent variable.

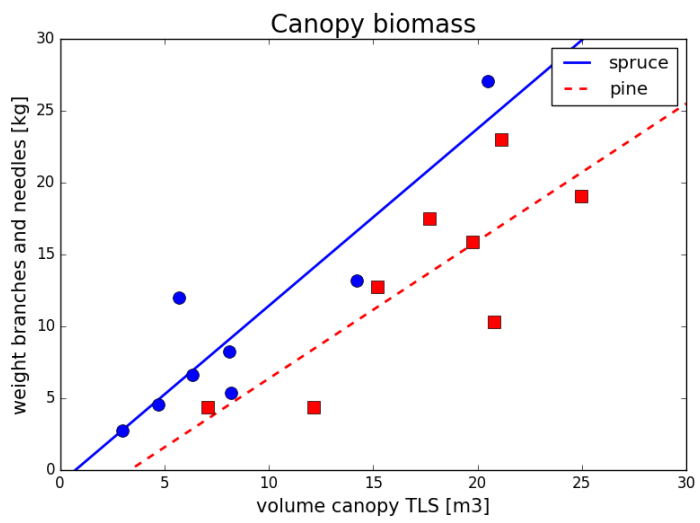

Figure 6. A linear model of canopy biomass (branches and needles) using TLS estimated volume as independent variable. The models are tree species specific which gives better model fits compared to building only one model for both tree species, Table 2.

\begin{tabular}{|c|c|c|c|}
\hline biomass class & $\mathrm{m}$ & $\mathrm{k}$ & RMSE $[\mathrm{kg}]$ \\
\hline canopy spruce & -0.90 & 1.23 & 2.95 \\
canopy pine & -3.20 & 0.96 & 3.75 \\
canopy both & 0.86 & 0.83 & 4.16 \\
stem both & -0.99 & 325.06 & 4.50 \\
\hline
\end{tabular}

Table 2. Tree biomass model parameters and RMSE for the model fit, Equations (2,3).

\section{ACKNOWLEDGEMENTS}

This research has received funding from the Advanced SAR EU project (FP7-SPA-2013.1.1-07) in the European Community's Seventh Framework Programme ([FP7/2007-2013]) under grant agreement no 606971. The field data published in the master thesis in forestry by Martin Goude at the Southern Swedish Forest Research Centre was used as ground truth. The terrestrial laser scanning was done by Tommy Andersson.

\section{REFERENCES}

Calders, K., Newnham, G., Burt, A., Murphy, S., Raumonen, P., Herold, M., Culvenor, D., Avitabile, V., Disney, M., Armston, J. and Kaasalainen, M., 2015. Nondestructive estimates of aboveground biomass using terrestrial laser scanning. Methods in Ecology and Evolution 6(2), pp. 198-208.
Goude, M., 2016. Can differences in leaf area, biomass and nitrogen content explain the production differences between scots pine (pinus sylvestris) and norway spruce (picea abies)? Master's thesis, Swedish University of Agricultural Sciences, SLU, Institutionen för sydsvensk skogsvetenskap, Alnarp, Sweden.

Hauglin, M., Astrup, R., Gobakken, T. and Nsset, E., 2013. Estimating single-tree branch biomass of Norway spruce with terrestrial laser scanning using voxel-based and crown dimension features. Scandinavian Journal of Forest Research 28(5), pp. 456469.

Henning, J. G. and Radtke, P. J., 2006. Detailed stem measurements of standing trees from ground-based scanning lidar. Forest Science 52(1), pp. 67-80.

Kankare, V., Holopainen, M., Vastaranta, M., Puttonen, E., Yu, X., Hyyppä, J., Vaaja, M., Hyyppä, H. and Alho, P., 2013. Individual tree biomass estimation using terrestrial laser scanning. $I S$ PRS Journal of Photogrammetry and Remote Sensing 75, pp. 6475.

Liang, X., Kankare, V., Hyyppä, J., Wang, Y., Kukko, A., Haggrén, H., Yu, X., Kaartinen, H., Jaakkola, A., Guan, F., Holopainen, M. and Vastaranta, M., 2016. Terrestrial laser scanning in forest inventories. ISPRS Journal of Photogrammetry and Remote Sensing 115, pp. 63-77.

Liang, X., Kankare, V., Yu, X., Hyyppa, J. and Holopainen, M., 2014. Automated Stem Curve Measurement Using Terrestrial Laser Scanning. IEEE Transactions on Geoscience and Remote Sensing 52(3), pp. 1739-1748.

Maas, H., Bienert, A., Scheller, S. and Keane, E., 2008. Automatic forest inventory parameter determination from terrestrial laser scanner data. International Journal of Remote Sensing 29(5), pp. 1579-1593.

Mengesha, T., Hawkins, M. and Nieuwenhuis, M., 2015. Validation of terrestrial laser scanning data using conventional forest inventory methods. European Journal of Forest Research 134(2), pp. 211-222.

Olofsson, K. and Holmgren, J., 2016. Single Tree Stem Profile Detection Using Terrestrial Laser Scanner Data, Flatness Saliency Features and Curvature Properties. Forests 7(9), pp. 123.

Olofsson, K., Holmgren, J. and Olsson, H., 2014. Tree stem and height measurements using terrestrial laser scanning and the ransac algorithm. Remote Sensing 6(5), pp. 4323-4344.

Olschofsky, K., Mues, V. and Köhl, M., 2016. Operational assessment of aboveground tree volume and biomass by terrestrial laser scanning. Computers and Electronics in Agriculture 127, pp. 699-707.

Raumonen, P., Kaasalainen, M., Åkerblom, M., Kaasalainen, S., Kaartinen, H., Vastaranta, M., Holopainen, M., Disney, M. and Lewis, P., 2013. Fast automatic precision tree models from terrestrial laser scanner data. Remote Sensing 5(2), pp. 491-520.

Seidel, D., Albert, K., Ammer, C., Fehrmann, L. and Kleinn, C., 2013. Using terrestrial laser scanning to support biomass estimation in densely stocked young tree plantations. International Journal of Remote Sensing 34(24), pp. 8699-8709.

Srinivasan, S., Popescu, S. C., Eriksson, M., Sheridan, R. D. and $\mathrm{Ku}, \mathrm{N}$.-W., 2014. Multi-temporal terrestrial laser scanning for modeling tree biomass change. Forest Ecology and Management 318, pp. 304-317.

Thies, M., Pfeifer, N., Winterhalder, D. and Gorte, B. G. H., 2004. Three-dimensional reconstruction of stems for assessment of taper, sweep and lean based on laser scanning of standing trees. Scandinavian Journal of Forest Research 2004(19), pp. 571-581.

Yu, X., Liang, X., Hyypp, J., Kankare, V., Vastaranta, M. and Holopainen, M., 2013. Stem biomass estimation based on stem reconstruction from terrestrial laser scanning point clouds. $R e$ mote Sensing Letters 4(4), pp. 344-353. 